\title{
Effect of Rivaroxaban on Fibrinolytic Therapy in Massive Pulmonary Embolism: Two Cases
}

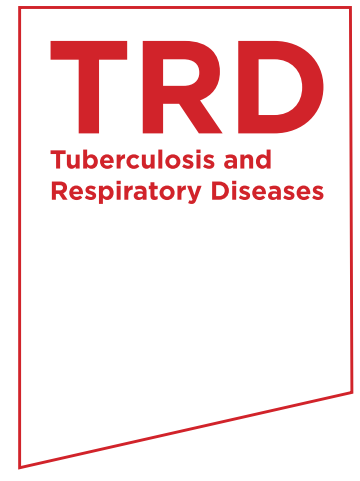

\author{
Hye-Jin Kim, M.D., So-My Koo, M.D., Nam-Suk Ham, M.D., Ki-Up Kim, M.D., Soo-taek Uh, M.D. \\ and Yang-Ki Kim, M.D.
}

Department of Internal Medicine, Soonchunhyang University College of Medicine, Seoul, Korea

\begin{abstract}
The risk of dying from a pulmonary embolism (PE) is estimated to be about $30 \%$ if inotropic support is required and no cardiopulmonary arrest occurs. Fibrinolysis in massive PE is regarded as a life-saving intervention, unless there is a high risk of bleeding following the use of the fibrinolytic therapy. Rivaroxaban is an oral factor Xa inhibitor, however its anticoagulation effects before or after administration of fibrinolytics in massive PE are still unknown. Two patents were admitted: 61-year-old woman with repeated syncope, and a 73-year-old woman was admitted with dyspnea and poor oral intake. Systemic arterial hypotension with radiologic confirmation led to a diagnosis of massive PE in both patients. Rivaroxaban was administered before in one, and after firbrinolytic therapy in the other. One showed similar efficacy of rivaroxaban with currently used anticoagulants after successful fibrinolysis, and the other one without antecedent administration of the fibrinolytic agent showed unfavorable efficacy of rivaroxaban.
\end{abstract}

Keywords: Pulmonary Embolism; Rivaroxaban; Fibrinolysis

\section{Introduction}

Massive pulmonary embolism (PE) is defined by acute PE with sustained systemic arterial hypotension that is below 90 $\mathrm{mm} \mathrm{Hg}$ for at least 15 minutes or requires inotropic agents ${ }^{1}$. The risk of dying of PE is estimated to be $30 \%$ if an inotropic support is required and no cardiopulmonary arrest occurs ${ }^{2}$. Fibrinolysis in massive PE is regarded as a life-saving intervention unless there is a high risk of bleeding following the use of fibrinolytic therapy ${ }^{3}$. Successful fibrinolysis reduces thrombus burden, rapidly reverses right heart failure, and leads to treat-

Address for correspondence: Yang-Ki Kim, M.D.

Department of Internal Medicine, Soonchunhyang University College of Medicine, 59 Daesagwan-ro, Yongsan-gu, Seoul 140-743, Korea

Phone: 82-2-709-9037, Fax: 82-2-793-9083

E-mail: kyklung@schmc.ac.kr

Received: Sep. 30, 2013

Accepted: Oct. 21, 2013

(c) It is identical to the Creative Commons Attribution Non-Commercial License (http://creativecommons.org/licenses/by-nc/3.0/).

Copyright (c) 2014

The Korean Academy of Tuberculosis and Respiratory Diseases. All rights reserved. ment with anticoagulation alone ${ }^{3}$.

Rivaroxaban, an oral factor Xa inhibitor and one of the new oral anticoagulants, shows effective anticoagulation within hours of administration, a fixed-dose regimen, and no need for laboratory monitoring ${ }^{4,5}$. The effect of rivaroxaban before or after administration of fibrinolytics in massive PE is still unknown since clinical trials performed with rivaroxaban excluded patients with massive PE. Here, we report on two cases of massive PE managed with fibrinolytic therapy and rivaroxaban.

\section{Case Report}

\section{Case 1}

A 61-year-old woman was admitted to our hospital with a 4-day history of repeated syncope. She had felt dyspnea on exertion even in daily life since the last 2 weeks. The loss of consciousness was accompanied by syncope but abnormal neurologic sign was not shown. She was never a smoker and had been on hormone replacement therapy for abnormal uterine bleeding since the last 3 months. On admission, blood pressure was 104/70 $\mathrm{mm} \mathrm{Hg}$, heart rate was 94 beat/min, re- 


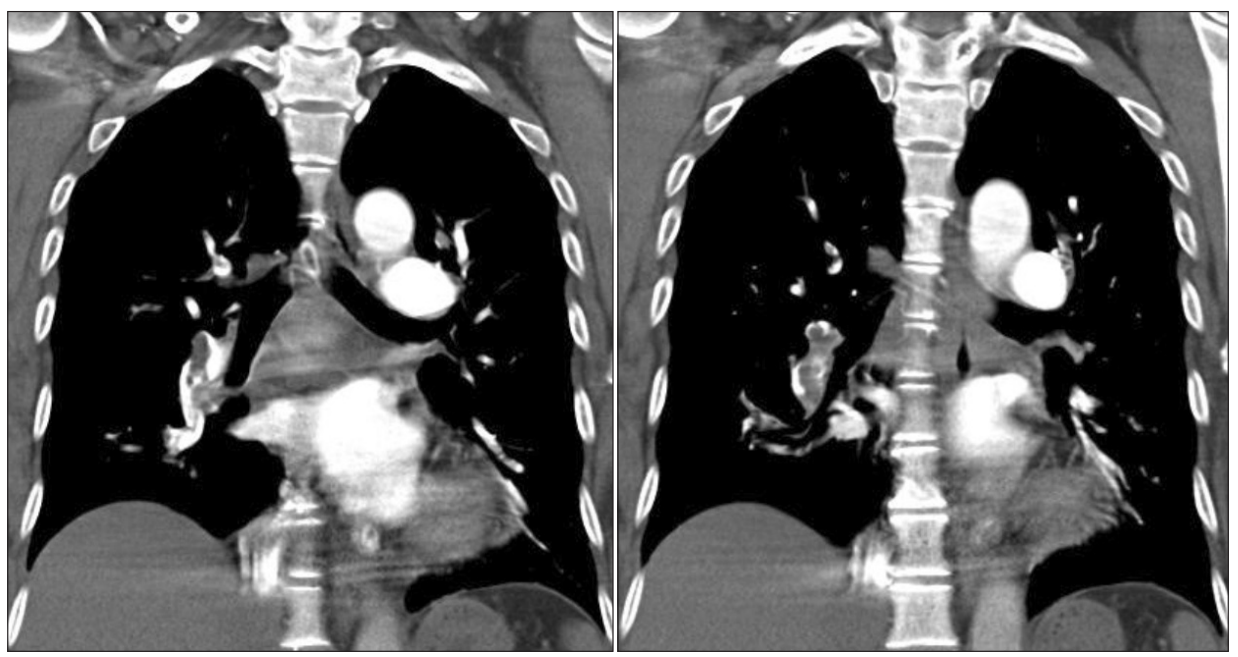

Figure 1. Computed tomographic pulmonary angiogram showed extensive bilateral acute pulmonary embolism and enlarged right cardiac chambers (case no. 1). spiratory rate was $20 \mathrm{breath} / \mathrm{min}$, and body temperature was $36.8^{\circ} \mathrm{C}$. All of a sudden, her blood pressure decreased to $80 / 40$ $\mathrm{mm} \mathrm{Hg}$ for over 15 minutes on the same day. The physical examination was grossly normal. Arterial blood gas analysis (aBGA) on room air was 7.442 in $\mathrm{pH}, 27.7 \mathrm{~mm} \mathrm{Hg}$ in $\mathrm{PaCO}_{2}$, $51 \mathrm{~mm} \mathrm{Hg}$ in $\mathrm{PaO}_{2}, 18 \mathrm{mmol} / \mathrm{L}$ in $\mathrm{HCO}_{3}{ }^{-}$, and $87 \%$ in $\mathrm{O}_{2}$ saturation. Echocardiography showed right ventricular (RV) hypokinesia with a D-shaped left ventricle (LV) and pulmonary hypertension. Computed tomographic (CT) pulmonary angiogram with lower extremity CT venogram showed extensive bilateral acute PE with deep vein thrombosis (DVT) in the right lower extremity and enlarged right cardiac chambers (Figure 1). The brain CT was normal. D-dimer, N terminal-probrain natriuretic peptide (NT-pro-BNP), and high sensitive troponin-T was 2,923 ng/mL (range, $0-243 \mathrm{ng} / \mathrm{mL}$ ), $316 \mathrm{pg} /$ $\mathrm{mL}$ (range, 0-97.3 ng/mL), and $0.029 \mathrm{ng} / \mathrm{mL}$ (range, 0-0.015 $\mathrm{ng} / \mathrm{mL})$, respectively.

According to the known protocol ${ }^{3}$ for massive PE, a high dose of unfractionated heparin (UFH) with 10,000 U was intravenously injected once. The maintaining dose of UFH was continuously infused at the rate of at least 1,250 $\mathrm{U} / \mathrm{hr}$ until the activated partial thromboplastin time (aPTT) reached 80 seconds. Then, recombinant tissue plasminogen activator (rt-PA) of $100 \mathrm{mg}$ was administered via a peripheral vein for 2 hours while a high dose of UFH was withheld. The aPTT was checked every 4 hours until aPTT reached below $80 \mathrm{sec}-$ onds. Rivaroxaban with $15 \mathrm{mg}$ twice daily was administered instantly without resumption of the high dose UFH after aPTT reached below 80 seconds. Her hospital stay was 4 days. The dose of rivaroxaban was changed from $30 \mathrm{mg} /$ day to $20 \mathrm{mg} /$ day after 3 weeks. Two months passed and she denied dyspnea on exertion even during hard work and any bleeding complications.

\section{Case 2}

A 73-year-old woman was admitted to our hospital with a 1-month history of dyspnea and poor oral intake. She had felt mild dyspnea on exertion without progression since last year. The aggravation of dyspnea on exertion started 1 month ago. She had a disability in walking because an event of cerebral hemorrhage occurred 2 years ago and an event of cerebral infarction occurred 1 year ago. She was never a smoker and was on medication due to hypertension for 2 years. On admission, blood pressure was $100 / 60 \mathrm{~mm} \mathrm{Hg}$, heart rate was 81 beat/ min, respiratory rate was 18 breath/min, body temperature was $36.4^{\circ} \mathrm{C}$. Her blood pressure decreased to $80 / 50 \mathrm{~mm} \mathrm{Hg}$ and lasted over 1 hour on the next day. aBGA on room air was 7.505 in pH, $23.1 \mathrm{~mm} \mathrm{Hg}$ in $\mathrm{PaCO}_{2}$, $64.6 \mathrm{~mm} \mathrm{Hg}$ in $\mathrm{PaO}_{2}$, $17.8 \mathrm{mmol} / \mathrm{L}_{\text {in }} \mathrm{HCO}_{3}{ }^{-}$, and $94.8 \%$ in $\mathrm{O}_{2}$ saturation. Echocardiography showed RV hypokinesia with a D-shaped LV and pulmonary hypertension. A CT pulmonary angiogram with a lower extremity CT venogram showed massive bilateral PE with lung infarction and DVT in the right superficial femoral vein extending to the popliteal vein (Figure 2). A brain CT showed an old infarction sequelae in the right frontal lobe, basal ganglia and cerebellum. D-dimer, NT-pro-BNP, and high sensitive troponin-T were 1,190 ng/mL (range, $0-243 \mathrm{ng} / \mathrm{mL}$ ), $17,481 \mathrm{pg} / \mathrm{mL}$ (range, $0-97.3 \mathrm{ng} / \mathrm{mL}$ ), and $0.036 \mathrm{ng} / \mathrm{mL}$ (range, $0-0.015 \mathrm{ng} / \mathrm{mL}$ ), respectively. Since previous intracranial hemorrhage is one of the major contraindications to the use of fibrinolytic therapy, high dose UFH alone was administered instead of a fibrinolytic agent. On the day following the high dose UFH injection, dyspnea was much improved in spite of no change in hemodynamic parameters. High dose UFH was replaced with rivaroxaban $15 \mathrm{mg}$ twice daily. After 3 days of medication with rivaroxaban alone, the dyspnea was worsened and repeated aBGA on oxygen $6 \mathrm{~L} / \mathrm{min}$ with an oxygen mask with a reservoir bag was $7.455 \mathrm{in} \mathrm{pH}, 19.3 \mathrm{~mm} \mathrm{Hg}$ in $\mathrm{PaCO}_{2}, 54.3 \mathrm{~mm} \mathrm{Hg}$ in $\mathrm{PaO}_{2}, 13.3 \mathrm{mmol} / \mathrm{L}$ in $\mathrm{HCO}_{3}{ }^{-}$, and $90.7 \%$ 

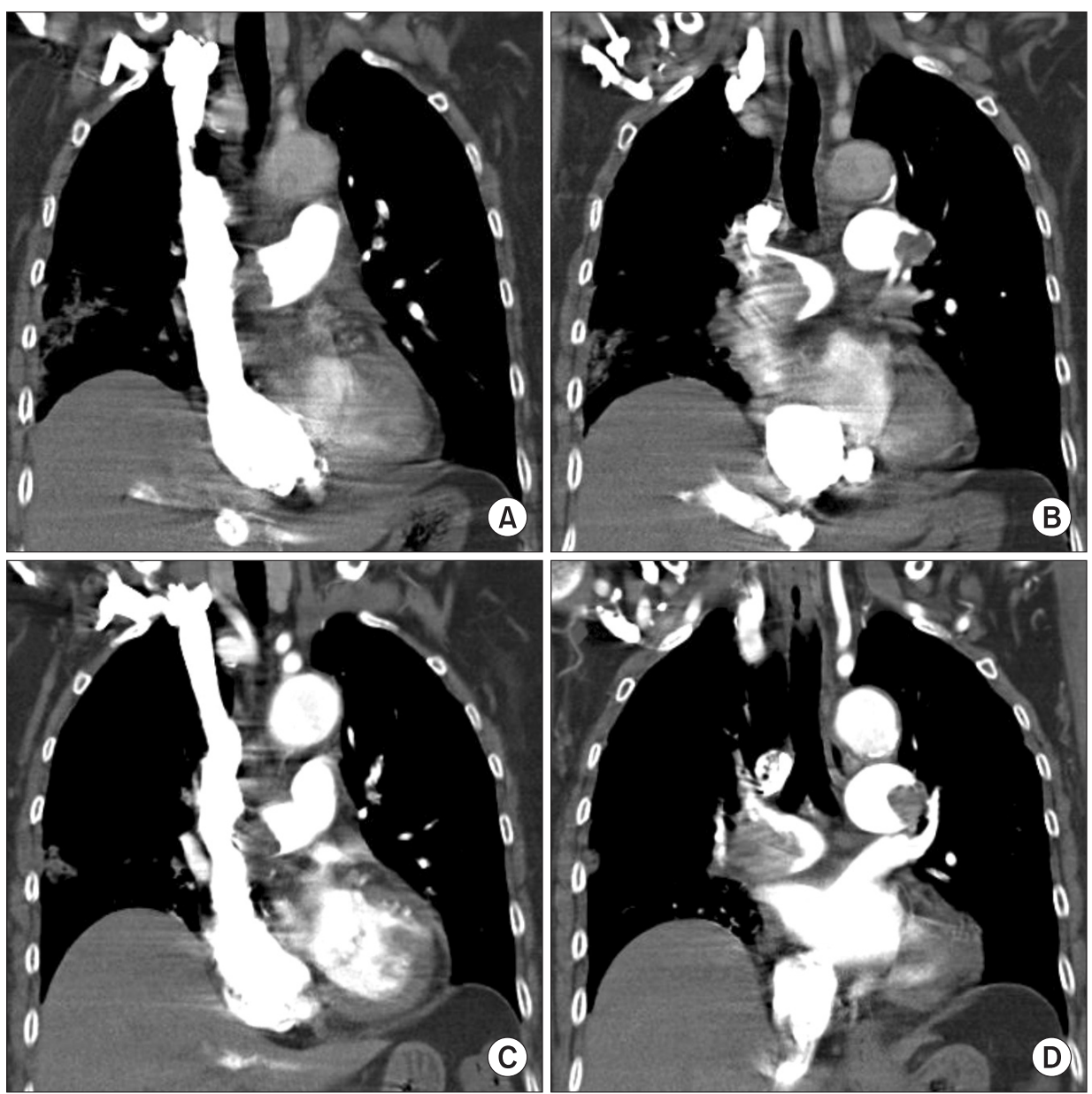

Figure 2. Computed tomographic pulmonary angiogram showed massive bilateral pulmonary embolism with lung infarction before (A, B) and after (C, D) administration of fibrinolytics (case no. 2).

\begin{tabular}{|c|c|c|c|c|c|c|c|c|c|c|c|c|c|c|c|c|c|}
\hline & Varc & $\mathrm{ICU}$ & \multicolumn{4}{|c|}{ Ward } & \multicolumn{6}{|c|}{ ICU } & \multicolumn{5}{|c|}{ Ward } \\
\hline HAD & 1 & 2 & 3 & 4 & 5 & 6 & 7 & 8 & 9 & 10 & 11 & 12 & 13 & 14 & 15 & 16 & 17 \\
\hline UFH & & & & & & & & & & & & & & & & & \\
\hline LMWH & & & & & & & & & & & & & & & & & \\
\hline Warfarin & & & & & & & & & & & & & & & & & \\
\hline Rivaroxabar & & & & & & & & & & & & & & & & & \\
\hline tPA & & & & & & & & & & & & & & & & & \\
\hline
\end{tabular}

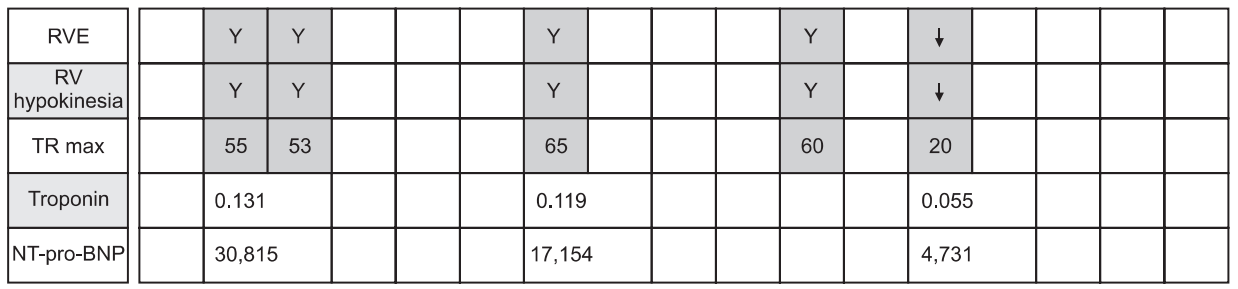

Figure 3. Flow chart on treatment methods, hemodynamic parameters, and location of management. ICU: intensive care unit; HAD: hospital admission day; UFH: unfractionated heparin; LMWH: low molecular weight heparin; tPA: tissue plasminogen activator; RVE: right ventricular enlargement; RV, right ventricular; TR max: maximum velocity of tricuspid regurgitation; NT-pro-BNP: N terminal pronatriuretic peptide.

in $\mathrm{O}_{2}$ saturation. A high dose of UFH was administered again after the rivaroxaban was stopped for 4 days. Dyspnea was slightly improved without a change in the thrombus burden on follow-up CT scan and hemodynamic parameters (Figure 2). We assumed that reversal of the RV failure outweighed the increased bleeding following fibrinolytic therapy. On the next 
day, rt-PA with $100 \mathrm{mg}$ was administered via a peripheral vein for 2 hours while a high dose of UFH was withheld. Dyspnea was much improved without major bleeding complications and hemodynamic parameters showed marked improvement (Figure 3). She has been taking warfarin after fibrinolytic therapy and denied dyspnea on exertion.

\section{Discussion}

The major determinant regarding favorable treatment outcome in these cases was whether a fibrinolytic agent was administered to patients with massive PE. A successful fibrinolysis, which reduces thrombotic burden and reverses RV failure, could lead to effective treatment following rivaroxaban alone and shorten the hospital stay (case no. 1). Initial treatment with rivaroxaban without fibrinolysis in massive PE failed to relieve RV failure (case no. 2). The effect of rivaroxaban as a first line drug in massive PE showed an unfavorable outcome.

In case 2, there was a major contraindication to the use of fibrinolysis owing to a previous intracranial hemorrhage. The relative risk of systemic fibrinolytic therapy is 3.5 within 35 days for major bleeding and 7 for intracranial bleeding ${ }^{2}$. At the time of diagnosis, high dose UFH was administered since the risk of increased bleeding following fibrinolysis outweighs the benefits of a rapid resolution to massive PE. Subsequent failures to relieve RV pressure overload with anticoagulant, such as rivaroxaban and high dose UFH, required escalation of therapy such as fibrinolysis because the benefits of a rapid resolution to PE outweigh the risk of increased bleeding following fibrinolysis.

In the case of massive PE with major contraindications to fibrinolysis, alternative treatment, such as catheter-assisted thrombus removal or surgical pulmonary embolectomy, is recommended if appropriate expertise and resources are available $^{2}$. The reasons why alternative treatment was not cho- sen were a slight improvement in symptoms after administration of anticoagulants and less probability it would progress to a cardiovascular collapse.

We report two cases with massive PE that successfully reverse RV failure with fibrinolytictherapy. In view of the administration of rivaroxaban in patients with massive $\mathrm{PE}$, one showed similar efficacy of rivaroxaban with currently used anticoagulants after administration of the fibrinolytic agent while the other one without antecedent administration of a fibrinolytic agent showed unfavorable efficacy of rivaroxaban.

\section{References}

1. Jaff MR, McMurtry MS, Archer SL, Cushman M, Goldenberg N, Goldhaber SZ, et al. Management of massive and submassive pulmonary embolism, iliofemoral deep vein thrombosis, and chronic thromboembolic pulmonary hypertension: a scientific statement from the American Heart Association. Circulation 2011;123:1788-830.

2. Kearon C, Akl EA, Comerota AJ, Prandoni P, Bounameaux H, Goldhaber SZ, et al. Antithrombotic therapy for VTE disease: antithrombotic therapy and prevention of thrombosis, 9th ed: American College of Chest Physicians evidence-based clinical practice guidelines. Chest 2012;141:e419S-94S.

3. Piazza G, Goldhaber SZ. Fibrinolysis for acute pulmonary embolism. Vasc Med 2010;15:419-28.

4. EINSTEIN-PE Investigators, Buller HR, Prins MH, Lensin AW, Decousus H, Jacobson BF, et al. Oral rivaroxaban for the treatment of symptomatic pulmonary embolism. N Engl J Med 2012;366:1287-97.

5. EINSTEIN Investigators, Bauersachs R, Berkowitz SD, Brenner B, Buller HR, Decousus H, et al. Oral rivaroxaban for symptomatic venous thromboembolism. N Engl J Med 2010;363:2499-510. 